\title{
O DEBATE SOBRE A REPRESENTACÃO POLÍTICA NO BRASIL: nota introdutória
}

\author{
Adrian Gurza Lavalle* \\ Cicero Araujo
}

O debate teórico sobre a representação política é surpreendentemente novo. A despeito de a representação ter sido amplamente pesquisada quanto a seus atores principais - partidos, parlamentares - e aos efeitos das regras que determinam quem e como pode ser eleito, bem como aos critérios de transformação dos votos em cadeiras nas câmaras - o sistema eleitoral -, o debate sobre o próprio conceito de representação contava, até os anos 1990, com um número literalmente minúsculo de referências obrigatórias. O livro seminal de Hanna. Pitkin, $O$ conceito de representaÇão, veio à luz em 1967 como a primeira tentativa de ordenar e integrar a produção dispersa sobre o tema, para além do campo da teoria do direito. ${ }^{1}$

* Doutor em Ciência Política pela Universidade de São Paulo (USP), Professor Doutor do Departamento de Ciência Política da USP e pesquisador e do Centro Brasileiro de Análise e Planejamento - CEBRAP (SP).

Rua Morgado de Mateus, 615. Cep: 04015902. Vila Mariana - São Paulo - Brasil. layda@usp.br

* * Doutor em Filosofia pela USP. Professor Livre-Docente do Departamento de Ciência Política da USP. craraujo@usp.br

${ }^{1}$ O longo texto de Giovanni Sartori "A teoria da representacão no Estado representativo moderno" é anterior foi publicado na Revista Brasileira de Estudos Políticos, de Belo Horizonte (MG), em 1962, mas tipicamente trava um debate no campo do direito e, mais especificamente, contra as interpretações dominantes dos juristas acerca da representação política.
Seu trabalho permaneceu como referência isolada durante quase três décadas, até a publicação, em 1995, de Os princípios do governo representativo, de Bernard Manin.

No espaço de 28 anos que separa ambas as obras, o espírito do tempo mudou. O livro de Pitkin se inscreve no plano de um esforço de clarificação e síntese filosófica sobre um conceito estabilizado historicamente, cujas concreções políticas, no governo representativo, e, mais especificamente, nas eleições, não manifestavam tendências de transformação nem fortes pressões ou críticas internas. Nesse sentido, o intuito “ordenador" do trabalho encerra seu percurso sobre as diferentes dimensões do conceito de representação, formulando uma síntese no campo da representação política e, em particular, focada no governo representativo, como sua modalidade mais relevante, sem, todavia, avançar qualquer avaliação sobre o próprio governo representativo. As críticas internas à democracia encetadas no bojo das mobilizações contraculturais dos anos 1960 e decantadas, uma década depois, no campo da teoria democrática e nos modelos participativos, encontraram eco no pensamento da autora, anos mais tarde, a propó- 
sito de uma revisão das mudanças históricas na representação política, publicada em 1989, em texto intitulado "Representação". ${ }^{2}$

Em contraposição, instalado na confluência entre a teoria política, a história do pensamento político e a história das instituições, o volume de Manin responde ao debate sobre a reconfiguração da representação. As transformações na economia e os programas de reestruturação característicos dos anos 1980 no hemisfério norte, acrescidos das transições no leste europeu, geraram, na literatura de diversas áreas e disciplinas, uma profusão de "crises" e "esgotamentos" da política, da democracia, do Estado, no primeiro caso, e da história, das ideologias, do trabalho, no segundo - apenas para citar alguns exemplos. Além disso, indicadores sobre identificação partidária, volatilidade eleitoral e confiança nas instituições políticas acusaram pioras significativas nas democracias mais tradicionais, dando ensejo a uma vaga de leituras críticas sobre os déficits de legitimidade. De fato, o trabalho de Manin constitui uma resposta aos diagnósticos sobre a "crise" da representação, a partir de uma reconstrução dos fundamentos do governo representativo, isto é, de suas instituições básicas e das intenções originais dos que as desenharam ou defenderam.

O debate teórico internacional tem se tornado mais denso nos últimos anos, e as perspectivas a partir das quais se vem tratando ora da crise, ora da reconfiguração da representação, multiplicam-se - teorias normativas, pós-modernas, dos campos da comunicação política, da sociedade civil, das relações internacionais e, claro, da própria teoria democrática. A propósito dos principais deslocamentos nesse debate, organizamos um número temático na revista Lua Nova, ${ }^{3}$ cuja acolhida favorável mostra o quanto os debates em curso trazem ganhos para a compreensão de questões emergentes e tradicionais que, a despeito de envolve-

${ }^{2}$ Traduzido ao português por Wagner Pralon Mancuso Pablo Ortellado, e publicado em número da revista Lua Nova dedicado ao "Futuro da Representação" (no. 67, 2006) sob o título "Representação: palavras, instituições e idéias".

${ }^{3}$ Ver nota anterior. rem a representação política, não tinham sido sistematicamente analisadas desse prisma.

Este número do Caderno CRH constitui um novo esforço de mostrar esses ganhos cognitivos, mas também uma tentativa de indicar algumas das frentes em que a representação política no Brasil está sendo repensada. Procuramos reunir artigos voltados para as instituições tradicionais da representação política e para novas instituições e práticas de representação, bem como abordagens que, olhando para o passado, buscam uma revisão historiográfica, tendo em conta questões atuais.

O artigo de Miriam Dolhnikoff aproveita uma das conseqüências analíticas do debate contemporâneo sobre a representação política para a historiografia, a saber, evidenciar o quão anacrônicas são as compreensões que vinculam diretamente o governo representativo com os princípios da democracia e com feições institucionais que aquele só viria a ter no século XX. Em revisão crítica da historiografia política do século XIX, a autora contesta a tese do falseamento institucional. É essa a compreensão mais difundida da representação no Império, como de resto da vida e instituições políticas no século XIX. Nela, os valores e propósitos formais da representação política teriam sido falseados devido à escravidão e, sobretudo, ao poder pessoal do Imperador, amparado pela existência do quarto poder - o Poder Moderador. Contudo, a análise do desenho institucional da monarquia representativa estabelecida no Brasil e sua comparação com o dos governos representativos existentes em países considerados berços da democracia - Inglaterra, França e Estados Unidos -, mostram não apenas que, a rigor, o Brasil tinha um regime representativo, mas que algumas das suas características eram peculiarmente progressistas para a época.

Levar a sério a vida das instituições representativas históricas do país pode ter como correlato não mais interpretar as disputas ideológicas e os empenhos intelectuais engajados em lhes redefinir princípios e operação no registro da superficialidade e do exotismo, como às vezes são tratados na literatura. Não surpreende, como atenta Cristina 
Buarque de Hollanda, no seu artigo, que as vertentes do debate intelectual sobre a representação política na Primeira República tenham recebido atenção mínima. No texto, a autora examina as concepções de representação sustentadas por liberais, positivistas e realistas, todos eles insatisfeitos com o funcionamento das instituições representativas de seu tempo, mas engajados na elaboração de modelos alternativos. Longe de se tratar de um escarcéu ilustrado e afastado de imperativos práticos, o texto mostra algumas das conseqüências desse debate quando seus protagonistas ocuparam posições de autoridade pública e implantaram mudanças institucionais.

Mesmo nos debates mais recentes sobre as características fundamentais do arranjo institucional pós-transição, a avaliação de suas supostas mazelas, concebidas no registro da paralisia decisória ou em outros registros, e as propostas de reforma que acompanham tais diagnósticos decorrem de elaborações que não têm interlocução direta com o debate teórico da representação. Antes, são diagnósticos preocupados com aquilo que, há anos, recebeu o nome de governabilidade. $\mathrm{O}$ artigo de Andréa Marcondes de Freitas é a esse respeito exemplar, quando examina um fenômeno aludido freqüentemente na mídia e que tem recebido atenção da literatura especializada, a saber, a migração partidária ou troca de partidos pelos representantes eleitos. A originalidade do texto reside em problematizar a questão do ponto de vista das teorias da representação, evidenciando não apenas que as posições no debate guardam relação com a agenda da governabilidade, mas que são pouco explícitas a respeito dos seus pressupostos no campo daquelas teorias. Em particular, as críticas à troca de partidos assumem que os partidos são os veículos corretos da representação; entretanto, há discrepâncias consideráveis no campo teórico da representação quanto aos vínculos adequados e aos efeitos da mediação partidária entre o eleitor e o eleito.

O artigo de Kathryn Hochstetler e Elisabeth Jay traz um deslocamento do olhar, atentando para as conexões entre, por um lado, as crises e a perda de credibilidade das instituições políticas tradicionais e, por outro, a mobilização social. Em análise comparativa entre Brasil e Argentina, as autoras indagam em que medida esses processos de mobilização significam uma desautorização dos partidos e do parlamento, e um eventual deslocamento para opções de representação supostamente mais próximas e menos engessadas, como aquelas encarnadas pelos movimentos sociais e organizações civis. O texto mostra que esses últimos ocupam lacunas deixadas pela representação no sistema de partidos, mas geralmente fazem-no de modo complementar, ora porque no Brasil esses atores nunca visaram a ocupar a posição dos partidos, mas a aprimorar e diversificar os canais de representação, ora porque, na Argentina, onde aquele propósito foi conjunturalmente almejado, os partidos recompuseram rapidamente suas relações com parte desses movimentos, e as instituições de governo recuperaram sua capacidade de tomar decisões com um mínimo de legitimidade - deixando aos atores da mobilização a porta das alianças e barganhas, e uma estrutura institucional mais sensível aos seus reclamos e participação.

Os três artigos seguintes abordam práticas e modalidades emergentes de representação que estão contribuindo para definir os contornos da pluralização da representação política no país, isto é, da diversificação do locus, das funções e dos atores da representação política para além do legislativo, das faculdades de controle da chefia do executivo e da proposição e sanção de leis, e do papel dos partidos políticos. Em artigo de teor comparativo informado por resultados de surveys originais, o artigo de Adrián Gurza Lavalle e Graziela Castello enfoca as novas funções de representação exercidas por organizações civis sediadas na cidade de São Paulo e na Cidade do México. Partindo do pressuposto de que a legitimidade das novas práticas de representação é crucial para as inovações democráticas ensejadas no país no contexto pós-constituinte, os autores se debruçam sobre as noções de representação política sustentadas por essas organizações que, em ambos os contextos, assumem a mediação dos 
seus beneficiários. O texto evidencia os ganhos cognitivos de se evitarem diagnósticos apriorísticos sobre a legitimidade ou ilegitimidade "inerente" àquelas práticas de representação. Ao decompor as noções de representação identificando as funções de controle sobre o poder público nelas supostas, bem como os eventuais mecanismos de accountability que as organizações civis mantêm com seus próprios beneficiários, o trabalho oferece um panorama das diversas lógicas e modalidades de representação presentes nesse universo.

Seguindo uma linha de fundo semelhante, o artigo de Lígia Helena Hahn se propõe a analisar certas experiências institucionais de democracia participativa no Brasil, supondo uma relação de complementaridade entre as noções de participação e representação. Isso significa entender aquelas experiências não como rejeições do próprio princípio representativo - uma conclusão nada infreqüente nas análises sobre elas -, mas como uma tentativa de sua assimilação, porém de formas não tradicionais. $\mathrm{O}$ artigo procura desenvolver esse ponto de partida comparando dois desses novos tipos de institucionalidade: os Conselhos Gestores e o Orçamento Participativo. O primeiro, claramente previsto no âmbito da reconstitucionalização do país depois de 1988, apresenta a peculiaridade de permitir a representação, não de indivíduos, mas de diferentes "coletividades", na medida em que tomam assento nesses conselhos tanto representantes de organizações civis quanto de órgãos estatais. Já o Orçamento Participativo, ao aproveitar a onda de criatividade institucional ensejada pela redemocratização, procura combinar formas de participação direta de indivíduos com mecanismos representativos que a própria estrutura decisória do Orçamento Participativo exige em seus momentos de afunilamento. Na verdade, como constata a autora, a participação direta é muito mais uma expressão do engajamento das organizações civis no processo de elaboração do Orçamento do que uma participação inteiramente não mediada de indivíduos. Enfim, fazendo essas e outras comparações, a grade analítica que combina a representação e a participação vai permitir à autora um entendimento mais amplo dessas experiências, inclusive na forma de novas problematizações.

Encerrando a série, o artigo de Rebecca Abers e Margaret Keck concentra sua análise nos Conselhos Gestores, mas tentando dar-lhes uma compreensão teórica suficientemente exaustiva para responder se poderiam efetivamente ser interpretados como uma experiência de representação. Após procurar diferentes enquadramentos que, ao fim e ao cabo, parecem não dar conta das peculiaridades dessa experiência, as autoras concluem que as funções comuns de "autorização e resposta" que costumam ser atribuídas à representação política não servem para definir os Conselhos Gestores. Buscando um caminho alternativo, na linha de certas visões deliberativas da democracia, elas acabam por dar-lhes uma compreensão inusitada: os conselhos deveriam ser vistos antes como um espaço de "relações fecundas", apto à "produção de definições e práticas de resolução de problemas", do que propriamente um espaço no qual um grupo de pessoas representa outras. Sem abandonar o termo representação para designá-la, essa compreensão parece de fato ir ao limite dos modelos teóricos disponíveis, o que não deixa de ser um modo interessante de realimentar o debate.

Para concluir a apresentação, os coordenadores deste dossiê gostariam de dirigir seus agradecimentos aos responsáveis pelo Caderno CRH, pelo estímulo original e pela oportunidade de oferecer ao público acadêmico brasileiro essa série de artigos. E são também especialmente gratos aos bolsistas de iniciação científica Roberta Soromenho Nicolete, Diogo Rodriguez e Livia Roncolato que, engajados no projeto, foram imprescindíveis na preparação e revisão de todo o material. 